\title{
AS ARTES INDÍGENAS E A ARTE CONTEMPORÂNEA
}

Regina Polo Müller

Este trabalho apresenta uma discussão sobre a arte nas sociedades indígenas situada no cenário da arte contemporânea. Abordam-se a pintura corporal, a arte gráfica e o ritual entre os Asuriní do Xingu, cotejando-os à arte conceitual e à arte da performance. A análise demonstra as noções do pensamento asuriní presentes nessas manifestações, bem como a contextualização e os processos que ocorrem em sua produção. Abordam-se também manifestações de outros povos indígenas, como os Kaxinawa, os Xavante e os Kayapó-Xikrin, relacionando-as a princípios filosóficos e valores éticos e morais, e se apresentam os rituais como performances cênicas. [Abstract on page 243]

ARTE GRÁFICA, ASURINÍ DO XINGU, RITUAL, ARTE CONTEMPORÂNEA, PERFORMANCE. 
Pensar sobre a arte nas sociedades indígenas pode situar-se no cenário da arte contemporânea, quando se tomam particularmente alguns de seus aspectos, como o movimento de ruptura dos sistemas de hábitos que a arte conceitual e a arte da performance instauraram, as tentativas de reflexão sobre questões sociais que as artes contemporâneas realizam e as funções que assumiram nas definições de identidade, trans e interculturalmente. Vemos, nos dias de hoje, artistas fazendo incursões no meio social, seja mapeando sua realidade, seja produzindo a partir de sua relação com ela. Vimos, enfim, no século XX, a arte tomar a cultura toda como referência, quando antes e a partir da Renascença existia como campo dela separado.

Aqui serão realizadas algumas aproximações entre linguagens e conceitos da produção da arte contemporânea e das artes indígenas, na atualidade, a partir de alguns exemplos, com ênfase na arte gráfica e nos rituais dos Asuriní do Xingu, povo tupi-guarani, da Terra Indígena Koatinemo, Estado do Pará. Contatados em 1971, são na atualidade aproximadamente 140 indivíduos.

Em primeiro lugar, dá-se já como superada a questão da definição de arte, bem como critérios para definir objetos e demais manifestações expressivas como arte no âmbito das culturas indígenas. Entendo, para resumir e simplificar um problema complexo, que a busca estética regulada por padrões e estilos e a natureza provocadora de processos de conhecimento e reflexividade, presentes nessas manifestações, permitem aproximá-la da produção artística contemporânea ocidental.

Observo, inicialmente, que, como demonstraram outros estudiosos (DIAS, 2000; LAGROU, 2005), a arte contemporânea que abandona o estatuto de arte como "domínio autônomo de julgamento humano" e como "um fim em si mesmo", plasmado da Renascença ao lluminismo, dirige seu interesse às práticas artísticas de sociedades indígenas por seu caráter integrado nos diversos domínios da vida social e sua natureza múltipla, ativa, participante e coletiva.

A noção de agência - a partir da qual se entende que, nas artes indígenas, objetos e demais manifestações expressivas são mais para provocar estados e processos de conhecimento e reflexividade, bem como transformações sociais ou ontológicas, do que para ser contemplados - vem mais diretamente auxiliar o estabelecimento de analogias com as manifestações da arte conceitual e da arte da performance, e, desse modo, contribuir para a exploração da ideia de contemporaneidade nas artes indígenas. As interações entre objetos e pessoas e entre objetos pensados como pessoas regulando estilos de produção artística (GELL, 1998) constituem, por exemplo, outra perspectiva de análise e compreensão da cultura material em sociedades indígenas na sua relação com os conceitos contemporâneos de obra de arte.

Para Lagrou (2005), exemplos de manifestações expressivas nativas demonstram que a "'eficácia da arte' inclui mais do que forma, mobilizando uma capacidade semiótica ou comunicativa específica, assim como uma capacidade de agência, pois, tanto quanto expressam, tintas, pinturas e objetos agem sobre a realidade de maneiras muito específicas, que precisam ser analisadas em contexto". E, citando Gell, Lagrou afirma que mais 
do que de uma análise meramente representativa, precisamos, portanto, de uma análise da agência dos objetos ou dos grafismos no contexto das interações sociais.

Para a autora, "o que caracteriza a pintura corporal e facial ritualmente mais eficaz e, portanto, mais apreciada no ritual de passagem de meninos e meninas kaxinawa é sua qualidade de ser mal em vez de bem feita: as linhas grossas aplicadas com os dedos ou sabugos de milho, com rapidez e pouca precisão, permitem mais permeabilidade da pele à ação ritual" constituindo a "(...) 'roupagem' liminar dos neófitos por causa de sua (...) suscetibilidade a processos de transformação".

No caso da pintura corporal asuriní, temos, como eficácia simbólica similar, o corpo todo pintado de preto, a aplicação da tinta de jenipapo não respeitando limites formais que distinguem os gêneros e marcam a anatomia humana. Trata-se aqui de "roupagem liminar", de estados de incorporação de personagens mitológicos na ação ritual de ritos cosmogônicos, como veremos adiante. Essa pintura, por sua vez, contrasta com a pintura com desenhos geométricos, também aplicados na cerâmica.

Distinguindo gênero e idade e reafirmando a natureza humana do suporte, essa pintura corporal realiza o que Lévi-Strauss (1975) chamou de "existência definitiva adquirida pela integração entre elemento plástico e o elemento gráfico", do mesmo modo como a decoração da cerâmica a realiza, unindo ornato e função utilitária. A aplicação dos desenhos geométricos no vaso cerâmico obedece aos limites que identificam sua forma (base, corpo, gargalo), que por sua vez se relaciona a sua função (cozinhar, transportar e armazenar alimentos).

Na decoração do corpo humano, pode ser usado qualquer motivo de desenho aplicado na cerâmica, o campo mais variado de formas e padrões decorativos utilizado. O padrão juaketé, entretanto, é o único usado com exclusividade na pintura corporal feminina. Nesse padrão, cujo nome se traduz por "pintura de verdade", a forma é parte de sua identificação e domina, portanto, o conteúdo. O desenho subordina-se à forma do corpo. Segundo Lévi-Strauss, nesse caso "a estrutura modifica a decoração, mas esta é a causa final daquela", "a decoração e a forma não podem ser, nem física nem socialmente, dissociadas" e ainda, "a decoração é concebida para o rosto [leia-se corpo], mas o próprio rosto [idem], não existe senão por ele: a dualidade é em definitivo a do ator e de seu papel..." (1975: 298).

No restante dos desenhos, a forma a eles se amolda sem que sejam alteradas as características formais, identificadas em qualquer suporte. O motivo juaketé, por sua vez, só se realiza na forma do corpo humano. O círculo de onde partem as linhas e os losangos que cobrem o tronco e as coxas é aplicado sobre a articulação das pernas ao tronco. O fundo da panela desloca-se no corpo para o círculo da articulação dos membros ao corpo, distinguindo a forma do objeto da forma humana. Juaketé segue o padrão tamakyjuak (losango) cuja tradução é "pintura de perna" (tamaky = perna, canela; juak = pintura). Esse padrão é usado preferencialmente do joelho até o tornozelo, parte da perna em que as meninas em geral treinam as técnicas da pintura. 
Próprio dessa parte do corpo, e pela analogia entre essa forma e a da panela de cerâmica, arredondada, o padrão "pintura de perna" é transposto para o objeto, obedecendo à mesma regra de divisão do espaço em superfície curva. No corpo como um todo, a duplicação de padrão juaketé a partir dos dois círculos na articulação de coxa e tronco, segue a anatomia do corpo, dividindo-o em dois, em dois sentidos: duas pernas e duas partes do corpo, membros inferiores e tronco.

A ornamentação do corpo com desenho geométrico, além de expressar um conteúdo relacionado à categorização social e outro relacionado à noção de máscara, isto é, a de indivíduo biológico e personagem social (LÉVI-STRAUSS, 1975: 298) possui outros sentidos, pois o elemento gráfico é realizado em outras formas além do corpo e não há dois estilos para diferentes suportes. Não se pinta apenas o corpo, mas os objetos diversos da cultura material. E em todos eles, o desenho único é abstrato, decorativo, mas igualmente simbólico, isto é, traduz noções básicas do pensamento, cujo conteúdo se encontra na própria forma do desenho e na tendência do estilo. Nesse sentido, trato a arte gráfica asuriní como "modelo reduzido", forma sintética da visão de mundo, de conhecimento, cuja metáfora está na própria estrutura formal, no estilo da arte visual (LÉVISTRAUSS, 1975: 45-46). É possível demonstrar essa extensão da arte gráfica aos diversos aspectos da cultura asuriní pela análise do estilo - a análise formal do produto da arte, do objeto em si.

Para se definirem características formais do desenho asuriní é importante, antes de tudo, perceber princípios de ordenamento do espaço e entendê-los por meio da relação entre percepção visual e processo cognitivo.

As técnicas de aplicação e o princípio de ordenamento do espaço ajudam a definir o estilo do desenho ou pelo menos suas tendências. Uma de suas características formais, a geometrização infinita do espaço, corresponde a um modo de percepção visual totalizante: a técnica do negativo/positivo encontrada na maioria dos padrões, combinada às outras técnicas, revela a maneira pela qual se percebe uma realidade visual. 0 claro-escuro, fundo e superfície conformam imagens. Por exemplo, os Asuriní identificam um conjunto de constelações pela imagem de uma onça atacando um veado. Entretanto, não são os pontos luminosos que delineiam as figuras, mas sim, os espaços negros entre eles, como os Asuriní nos ensinam a ver.

A geometrização do infinito através de formas abstratas (cujos nomes e referem aos três domínios cosmológicos) e a totalização do espaço como modo de percepção visual particular são tendências que definem o desenho. Elas, por sua vez, têm correspondência com um princípio estruturante da cosmologia asuriní. Relacionando percepção visual e princípios do entendimento na arte gráfica asuriní, pode-se dizer que geometrização infinita do espaço mistura domínios cósmicos através das abstrações visuais de conteúdo simbólico com referentes do(s) mundo(s) que os cerca(m), como se, por exemplo, a mata e seus seres fossem vistos através de formas ligadas ao sobrenatural (as variações "cangote de onça" e "patas de jabuti" seguem o padrão tayngava, nome da figura antropomórfica usada nos rituais xamanísticos). A "mistura" ou "sobreposição" de diversos do- 
mínios participa do cotidiano, e os xamãs os visitam e se transformam nessas criaturas diferentes domínios cósmicos se sobrepõem através da percepção visual de um mundo geometrizado em abstrações formais que os misturam para separá-los novamente, numa classificação conforme a nomenclatura dada (nomes ligados à natureza, à cultura e ao sobrenatural e relacionados às categorias formais da arte gráfica como padrão, variação do padrão e desenho).

A inter-relação dos domínios cosmológicos no desenho geométrico corresponde à estrutura formal desse sistema visual: o padrão, entendido no sentido de regra formal, corresponde ao sobrenatural, e a variação, realizada segundo esse padrão, se refere à natureza e aos homens (à cultura), domínios submetidos a uma relação com o mundo sobrenatural. Assim, a regra formal das variações cujos nomes se referem a animais, plantas, artefatos e grafismos é ditada pelo padrão tayngava - ângulo de $90^{\circ}$ - cujo referente é um elemento simbólico ligado ao sobrenatural.

Os padrões são noções abstratas e sua realização concreta se dá através dos desenhos nos objetos e no corpo. O conteúdo semântico das variações de um padrão, o seu nome a partir de um referente do mundo real, está relacionado aos domínios da natureza e da produção cultural. Do padrão tayngava temos, por exemplo, o motivo "pata de jabuti" ou o motivo do enfeite labial: trata-se de variações da 'grega', forma básica da maioria dos desenhos asuriní. Os demais padrões possuem poucas variações como as do padrão tamakyjuak (losangular): tamakyjuagí, mytupepá. Às vezes, as variações de um padrão apresentam mínimas diferenças morfológicas como o kwasiarapara (diagonal). Assim, a forma tayngava tem preponderância sobre as outras no sentido estatístico e semântico. Cobre categorias como padrão, variação e desenho e natureza/sobrenatural/ cultura. Isto Ihe dá destaque na estrutura formal dos desenhos: o "padrão", correspondente ao sobrenatural, é eixo determinante (regras) da realização dos desenhos com vários significados relacionados à natureza e à cultura; a "variação", correspondente ao nível do conteúdo, faz referência aos três domínios cosmológicos, e "desenho" corresponde ao produto final realizado concretamente através dos suportes.

A preponderância formal do tayngava está relacionada à importância da noção que o elemento básico desse padrão representa e o nomeia: a figura antropomórfica, objeto ritual xamanístico cujo nome se traduz como 'imagem humana' ( $t=$ possuidor humano; ayng= imagem+av (a) = sufixo formador de nome de circunstância).

Outro aspecto formal da estrutura do desenho asuriní, e desse padrão em particular, deve ser notado como princípio ordenador, ao lado da geometrização infinita e totalização do espaço. Este, como vimos, está relacionado à mistura e separação de esferas cósmicas no pensamento asuriní. O outro, à noção mais ampla de diferente e igual, variação e repetição. Trata-se das duas orientações formais básicas nos desenhos que desenvolvem o padrão tayngava: (1) assimetria de desenhos que podem ser executados livre e infinitamente, variando a unidade elementar do padrão (pela técnica que chamamos de extensão). Na maioria dos casos coincide com as criações individuais; (2) simetria de desenhos que repetem módulos (termo que designa justamente uma forma mais codificada 
e mais tradicional da arte gráfica asuriní), elementos isoláveis do sistema. Sua execução parece exigir maior perícia da autora, pela geometrização simétrica exata da área a ser decorada, isto é, a repetição da mesma forma até preencher totalmente a área.

A primeira orientação é de variação, diferenciação, a unidade elementar se apresentando de diferentes maneiras. A segunda é repetição, igualdade, a unidade elementar se apresentando igual - polissemia no primeiro caso, paráfrase no segundo.

Por outro lado, na variação, a unidade é sempre a mesma, e, na repetição, o segundo é o outro: mais de uma unidade é necessária para compor igualdades. Temos assim, no desenho asuriní, simetria e assimetria, o jogo de relação entre o igual e o diferente, presente em outros sistemas cognitivos da cultura como a cosmologia, o ritual e a mitologia.

Procurei demonstrar nesses estudos que no próprio estilo de técnica do desenho geométrico encontra-se o conceito visual (ARNHEIM, 1980) da noção de representação entre os Asuriní, identificando-a através da compreensão da cosmologia e dos rituais xamanísticos. Tanto a arte gráfica quanto a ação ritual foram analisadas enquanto discurso não verbal, de modo a acessar o que chamei de materialidade ou marcas formais de uma discursividade que é processual e possível de ser contextualizada para além de relações estruturais que uma análise semiótica poderia estabelecer. Enquanto discursos, pude dar conta de processo e contextualização para detectar princípios organizacionais do que chamo aqui de estilo e técnica. Lançando mão também da análise da narrativa mítica, verifiquei propriedades como a posposição e junção das informações no texto mítico, ou seja, concomitância de sentidos e não causalidade e hieraquização. Esse princípio corresponde à noção de par e concomitância de estados de alteridade, detectada em outras manifestações do pensamento asuriní.

No ritual muraaja, realizado pelo xamã e outros participantes, homens e mulheres, trazem-se à aldeia, através de canto e dança, espíritos e divindades - seres habitantes de diversos planos cósmicos. O ritual é expressão, em todos os atos que desenvolve, do contato íntimo e ao mesmo tempo ambíguo com esses seres: dança-se com eles, fuma-se junto, oferece-se a comida, mas também se mantém com relação a eles comportamento igual ao que se tem com a presa animal, tentando-se pegá-la agressivamente. Os ruídos que o xamã faz, seus gestos de pegar algo no ar, seus gemidos dentro da tukaia (cabana de folhas para onde são atraídos os espíritos), demonstram essa relação de conflito. Essa experiência de intimidade com os espíritos é vivida pelo xamã, seus assistentes e mulheres jovens que cantam e dançam, acompanhando-o. A maneira pela qual a dança se realiza manifesta essa participação conjunta do contato com os espíritos: todos os corpos se tocando, um abraçado ao outro, e, quando há duas filas, o assistente abraça-se numa cantora com uma das mãos e, com a outra, toca o corpo do xamã, a sua frente. Se, de um lado, está presente uma legião de espíritos (são vários os que vêm à cabana tukaia), de outro, os humanos também participam coletivamente, num bloco de corpos, marcando sua "humanidade" comum. E, dançando em grupo diante da cabana, opõemse a eles, que ali estão hospedados. 
O contato entre humanos e espíritos realiza-se, mas é ameaçador. Há conflito e ambiguidade nas relações entre espíritos e humanos. Para os demais humanos, não xamãs, a participação no ritual é perigosa, mas inevitável: a participação do assistente e das jovens dançarinas determina a comunhão de humanos e espíritos.

Estamos tratando aqui de noção fundamental na cosmologia asuriní para a compreensão dos seres e do próprio pensamento sobre o universo: a concomitância de planos cósmicos, que é vivenciada pelo xamã asuriní metamorfoseado em um ser sobrenatural, tornando-se um deles. Ao mesmo tempo, permanece humano, ambivalência que, como vimos, se encontra na ação ritual. Por meio da metamorfose do xamã, organizamse relações entre humanos e espíritos, isto é, entre seres diferentes, princípio ordenador da sociedade, garantindo-se nessa ação a operacionalização desse princípio estruturante da sociedade. Nessa ação, ainda, a própria relação entre o performer e o espectador (os demais membros do grupo, entre eles os que assistem e os que participam da performance) faz parte da significação. Esse princípio dialógico e o caráter experiencial do ritual xamanístico permitem realizar as aproximações que anunciamos no início desta comunicação. Entendemos que a reflexão sobre a experiência ritual é esclarecedora de outras experiências com caráter de "drama plástico", experiência sensível que se fundamenta na ética e na estética, constituindo modelo para a crença ou, ainda, "conteúdos simbólicos que incorporam ethos e eidos" (GEERTZ, 1978) segundo o autor dessa definição que, a nosso ver, se aplica tanto a rituais indígenas quanto à forma contemporânea ocidental de experiência artística, a arte da performance. Assim como o ritual atualiza conteúdos cosmológicos estruturantes da sociedade, por meios estéticos de representação, a performance artística, também por meios estéticos, atualiza conteúdos do universo individual do artista em sua relação com o meio. Podemos também entender ambas enquanto processo de significação, como "construção de formas culturais de se viver a vida, compartilhadas por meio dos sentidos pelo grupo ou pela sociedade a que se pertence" (GEERTZ: 1986).

A situação de dialogia e o caráter processual/experiencial são aspectos que privilegiamos para relacionar ritual e arte da performance. Do caráter processual/experiencial, destacamos agora a reflexividade inerente à performance em geral (cultural, nos termos de SINGER, apud TURNER, 1988) para cotejá-la à prática reflexiva definidora, por exemplo, do "programa ambiental” de Hélio Oiticica, segundo Favaretto (1992: 128): “... o ambiental é uma prática reflexiva; estrutura-se como Retórica (da ação e do movimento), aproximando-se dos relatos e dos mitos... As operações ambientais evidenciam a produção como significativa: não o constituído, o processo de constituição, dessublimando-se as experiências".

A participação como elemento desse processo fundamental de constituição do significado remete à concepção do artista tal como colocada por Favaretto a respeito das propostas de Oiticica, segundo a qual não é ele um "criador de objetos para a contemplação... se torna um motivador para a criação... Esse deslocamento aponta para uma nova inscrição do estético: a arte como intervenção cultural. Seu campo de ação não é o siste- 
ma de arte, mas a visionária atividade coletiva que intercepta subjetividade e significação social. A antiarte, entendida como série de proposições para a criação, tem pois como princípio a participação"(idem, ibidem:124).

Poder-se-ia pensar, a partir desse exemplo comparativo, que o xamã e o artista são "motivadores" da "experiência formativa", seja ela entendida como ação reflexiva na avaliação da existência, seja como intervenção cultural.

Da antropologia da performance tomo ainda outras referências teóricas para dar continuidade a estas comparações. De acordo com Turner (1988), o ritual indígena pode ser compreendido como o modo pelo qual um complexo de ações performáticas e meios de comunicação sensorial, visual e sonora, de grande variabilidade, faz emergirem significados que permitem o exercício da reflexividade sobre a experiência social, a "parede de espelhos" a que se refere Turner (1988:24). A dimensão estética do ritual se encontra, desse ponto de vista, no entendimento de que sua relação com um sistema social ou configuração cultural não é meramente os refletir ou expressar, unidirecionalmente, mas sim de reciprocidade e reflexividade. A grande variabilidade de ação e de meios de comunicação produz um conjunto de mensagens sutilmente variáveis, resultando numa "parede de espelhos - espelhos mágicos, cada qual interpretando, bem como refletindo, as imagens neles lançadas e emitidas de um para outro".

Do uso da máscara às danças, músicas e ações teatrais que compõem as performances rituais dos povos indígenas, são inúmeros os aspectos que podem ser abordados de modo a se destacar seu lugar proeminente nos sistemas expressivos das artes indígenas no Brasil. Já se descreveu o uso da máscara como "iconografia materializada em forma tridimensional e extrassomática que assume expressão somática no contexto da atividade ritual e coreográfica" através da qual "premissas filosóficas sobre a ordem macrocósmica são trazidas ao plano da experiência sensorial do indivíduo" (VINCENT, 1986: 160). Para além dessa natureza sensorial, tátil, visual e sonora dos códigos simbólicos que estruturam as manifestações expressivas nos rituais e assim reordenam o pensamento (idem, ibidem), nos aprofundamos no caráter reflexivo dessa experiência estética, aproximando esses rituais da arte teatral.

Desse modo, os abordamos como performances cênicas, nas quais diferentes linguagens se integram: dança, música, artes plásticas (adereços, objetos, pintura corporal), teatro (ritos e incorporação de personagens), literatura (narrativas míticas, discursos rituais) e cenografia (organização espacial para a ação ritual).

Da perspectiva da antropologia da performance, acrescento ainda o caráter lúdico que o ritual e a arte da performance compartilham. Em ambos, a ação e a expressão corporal tomam a cena, o "meio torna-se a mensagem", sendo, ao mesmo tempo, o agente transformador. Assim ocorre com o estado de transe do xamã, resultado de dança e canto (respiração e movimento), cuja forma estética presentifica o ser metamoforseado, bem como com a incorporação de personagens míticos no ritual cosmogônico. Ao lado da fisicalidade constitutiva da performance, essa mesma forma é o simulacro do eu, a experiência de que elementos que são "not me" se tornem " $m e$ " sem perder sua "not 
me-ness". "Eu" e "não eu", o perfomer e a coisa a ser performada, são transformados em "não... não eu" por meio do laboratório/ensaio/ processo ritual. Esse processo ocorre em tempo/espaço liminar e no modo subjuntivo" (SCHECHNER, 1985: 112).

Podemos dizer que nos rituais xamanísticos dos Asuriní do Xingu o movimento do corpo esteticamente organizado, a dança, conforma - dá forma - a manifestação do personagem (o espírito presente) bem como as ações dos demais personagens da trama cósmica, fundada na relação de alteridade. Desse trânsito entre planos e da troca entre seres depende a ordem do cosmo, sua reprodução e, consequentemente, a sobrevivência dos humanos.

No ritual cosmogônico das flautas turé, os personagens incorporados na ação performática, desenvolvida pelas danças e cerimônias, são o morto e o matador, dos scripts dos mitos de origem. A dança no pátio externo em frente à casa comunal em que estão enterrados os mortos consiste na coreografia de um grupo de tocadores de flauta em linha e acompanhados por mulheres, que compreende evoluções num cortejo circular, no qual de vez em quando se destaca um casal solista. Os homens, primeiramente, se reúnem dentro da casa tocando os instrumentos para, em seguida, sair para o pátio e dançar com as mulheres acompanhantes e demais participantes da comunidade, outras mulheres e crianças que se juntam às principais parceiras dos tocadores. Todos os tocadores desempenham a função de executar a música (tocando e dançando) que, junto com o choro ritual, afasta os mortos para sempre da vida dos vivos, garantindo a ordem cósmica de separação e convivência entre seres diferentes. Diz o mito que Kavara, um avá (humano), e seu companheiro estavam caçando na mata e foram atacados por inimigos.O companheiro morreu, e Kavara, sobrevivente, voltou à aldeia. Nesse retorno, foi perseguido pelo anhynga do companheiro morto: pedaços do corpo, como fígado coração, braço, perna, sangue. Kavara e os pedaços do morto chegaram à aldeia e realizou-se, então, um ritual no qual tocaram-se as flautas e dançou-se em torno do braço do morto. Dançou-se a noite toda, e, pela manhã, o anhynga foi embora. Os indivíduos que desempenham o papel de Kavara têm o corpo todo pintado de preto e colocam penugem de gavião na cabeça e nas pernas, investidura dessa condição mítica e sobrenatural.

O cortejo liderado pelo personagem/papel ritual do Kavara tocador de flauta que se inicia na casa dos visitantes tocadores de flauta, dirige-se à casa comunal e retorna à casa dos visitantes - pode ser interpretado como a transmutação simbólica do guerreiro (o matador) no representante do morto (o sobrevivente Kavara), sintetizando, na ação performática, um princípio da cosmologia e ontologia asuriní. O guerreiro é o outro lado da moeda: o guerreiro é tatuado, e o morto, chorado. A tatuagem separa substancialmente o matador da vítima, com a extração do sangue de seu corpo, e o choro ritual sobre a sepultura separa cosmicamente morto e vivo. Durante o cortejo da transmutação, o canto sobre a parte do corpo do morto, realizado pelo sobrevivente Kavara, também chamado guerreiro, garante a unidade do eu (a pessoa), separando os dois domínios, vida e morte, vivos e mortos, matador e morto. 
A ação ritual - cortejos, danças e ritos cerimoniais - que se desenvolve entre a casa comunal e a casa dos visitantes, de um lado, realiza a passagem entre esferas cósmicas e estados ontológicos e, de outro, estabelece relações entre estes níveis: vivos e mortos, humanos e espíritos, Asuriní atuais e ancestrais.

Do ponto de vista do espaço, o ritual estabelece relações cósmicas e sociais entre categorias "diferentes" de seres, sejam sobrenaturais e humanos, sejam visitantes e anfitriões. Durante a realização do ciclo de rituais turé, a casa comunal se abre e, com o pátio externo e a casa dos visitantes, se torna o próprio cosmo em que o mundo dos humanos se relaciona com as demais esferas cósmicas. A construção da cabana tukaia para atrair/ hospedar os espíritos nos rituais xamanísticos também transforma o espaço da aldeia naquele da convivência cósmica entre seres dos diferentes planos da realidade asuriní. Tão importantes para a reprodução social quanto os vivos da aldeia são os seres ancestrais mitológicos e os espíritos que povoam o cosmo asuriní e participam da vivência humana, através dos rituais.

Entendidos como manifestações artísticas, esses rituais constituem experiências estéticas através das quais essas sociedades realizam a formação dos indivíduos, a transmissão de saberes, do conhecimento sobre a cosmologia e da possibilidade de se vivenciar a existência em diferentes planos do cosmo.

Moldando corpos, percepção e sensibilidade, criação e fruição estética, através de sensações que o deslocamento no espaço propicia, a experiência da dança, por exemplo, promove a superação da condição humana através da ilusão de conquista da gravidade (LANGER, 1980). A ornamentação corporal nos rituais kayapó-xikrin, como veremos adiante, promove igualmente essa superação.

Entre os Xavante, povo Jê, habitante do Brasil Central, Estado do Mato Grosso, as relações entre gêneros, entre categorias sociais (jovens, adultos, líderes de grupos políticos e linhagens, etc.), entre grupos sociais (metades exogâmicas, grupos de idade, etc.) são expressas e constituem objeto da experiência sensível nas performances rituais.

Princípios filosóficos e valores éticos e morais são assim transmitidos através da experiência estética na construção da identidade e reprodução da sociedade.

Entre os kayapó-xikrin, povo Jê, habitante da Amazônia, Estado do Pará, os rituais mais importantes são os ligados à iniciação e à nominação. Como Vidal (1977) descreve, rituais de iniciação marcam a passagem do indivíduo do sexo masculino da fase pubertária à maturidade. Nos rituais de nominação, indivíduos dos dois sexos recebem seus nomes cerimoniais. Intimamente relacionada às atividades sazonais de caça, coleta, pesca e agricultura, a nominação pode ocorrer, por exemplo na festa do milho que por sua vez é combinada com o ritual das máscaras kukoi (macaco-prego) e pot (tamanduá). Desenvolvidos paralelamente em várias ocasiões, os rituais de nominação e de iniciação acompanham o ciclo anual das atividades de susbsistência na aldeia, atribuindo-lhes expressão ritual. 
Vidal (1992) observa que nos rituais de nominação e iniciação entre os Kikrin, a pintura corporal é complementada pela ornamentação com artefatos plumários, de cera, algodão e palha, todos fabricados pelos homens, e a descreve no caso do ritual de nominação feminina nhiok, no qual há sequência de pintura corporal e de ornamentação utilizadas por diferentes personagens. De acordo com a pesquisadora, a estampa de jenipapo das meninas nhiok, aplicadas com estilete, exprime simbolicamente a "socialização" do corpo humano. O uso de tintura de carvão e de pó azul da casca do ovo da ave tinamus, pelos homens, representa um processo de transformação. No ritual de nominação feminina nhiok percebe-se a transformação da onça em gavião, assim como das nominadas em beija-flores, aptas a voar. A onça ornamenta-se e grita como o gavião, indicando que ela é especial e, simultaneamente, os dois animais. As onças-gaviões auxiliam na aquisição da identidade humana e social ao possibilitar às iniciadas a obtenção, em si, da essência das aves. Assim, o ritual afirma a existência de uma onça-gavião em um mundo no qual os humanos são homens-aves (GIANNINI apud VIDAL, 1992: 174).

Em todos os rituais importantes, os Kayapó se enfeitam aplicando na face máscaras de pó de casca de ovo de ave tinamus, colando penugens - nos cabelos, de urubu-rei e, no corpo, de periquito - e portando imponentes diademas de plumas. É o processo de transformação em aves, tal como já descrito. Em outras ocasiões vestem ainda grandes máscaras de folhas de palmeiras e entrecascas, transformando-se em macacos, tamanduás e aruanás (idem, ibidem: 176).

Essas manifestações denunciam a vontade de ultrapassar as condições da existência humana, pois os Kayapó-Xikrin do Pará se "consideram aves, profundamente insatisfeitos com sua condição apenas terrestre, impossibilitados de usufruir uma visão panorâmica - entenda-se estética - do mundo e de suas belas aldeias circulares" (VIDAL, 2001: 17).

Seja como "instrumentos da revelação" (VIDAL, 1992), seja como "performance cultural" (SINGER apud TURNER, 1988), isto é, "uma avaliação do modo pelo qual a sociedade lida com a história", os rituais aqui descritos e analisados constituem performances cênicas esteticamente estruturadas - incluindo meios não linguísticos, como a música, a dança, a arte teatral e as artes visuais - através das quais conteúdos dados da cultura (noções e valores), a tradição ou o passado são reelaborados no presente, com vistas ao futuro, a fim de garantir continuidade e reprodução em processo.

\section{REFERÊNCIAS BIBLIOGRÁFICAS}

ARNHEIM, R. Arte e percepção visual, uma psicologia da visão criadora. São Paulo: Edusp, 1980.

DIAS, J.A.B.F. Arte, arte índia, artes indígenas. In Mostra do redescobrimento, Brasil, 500 anos é mais. Vol. Artes Indígenas. São Paulo: Fundação Bienal de São Paulo, 2000.

FAVARETTO, C. A invenção de Hélio Oiticica. Texto\&Arte, 6, São Paulo, 1992.

GEERTZ, C. A interpretação das culturas. Rio de Janeiro: Zahar Editores, 1978. 
Making Experience, Authoring Selves. In: Turner,V.W. e Bruner,E.M.(eds). The Anthropology of Experience. Urbana/Chicago: University of Illinois Press, 1986.

GELL, A. Art and agency. An Anthropological theory. Oxford: Clarendon Press, 1998.

GRUPIONI,L.D.B. Native traditions: an encounter with the material culture of Amazonian indigenous peoples. In Amazonia. Native traditions. Beijing: The Palace Museum, BrasilConnects Cultura \& Ecologia, 2004.

LAGROU, E. L'art des indiens du Brésil. Alterité, "authenticité"et "pouvoir actif". In Brésil indien, les arts des amérindiens du Brésil. Paris: Réunion des Musées Nationaux, 2005.

LANGER, S. Sentimento e forma, São Paulo: Perspectiva, 1980.

LÉVI-STRAUSS, C. Antropologia estrutural. Rio de Janeiro: Tempo Brasileiro, 1975.

SCHECHNER, R. Between theater and Anthropology. Philadelphia: University of Pennsylvania Press, 1985.

TURNER, V.W. The Anhropology of performance. Nova York: PAJ Publications, 1988.

VIDAL, L. Morte e vida de uma sociedade indígena brasileira. São Paulo: Hucitec/Edusp, 1977.

A pintura corporal e a arte gráfica entre os Kayapó-Xikrin do Cateté. In Grafismo indígena, estudos de antropologia estética. São Paulo: Studio Nobel/Fapesp/ Edusp, 1992.

. As artes indígenas e seus múltiplos mundos. In Revista do Patrimônio Histórico e Artístico Nacional, n. 29, Brasília, 2001.

VINCENT,W.M. Máscaras.Objetos rituais do Alto Rio Negro. In Ribeiro,B.G. (coord.). Suma etnológica brasileira. Petrópolis: Finep/Vozes, 1986.

Regina Polo Müller é doutora em antropologia pela Universidade de São Paulo e autora do livro Os Asuriní do Xingu: história e arte. 